\title{
A Simple Procedure for Comparative GC-MS Analysis of Lavender (Lavandula Angustifolia Mill.) Flower Volatile Composition.
}

\author{
Tzvetelina Zagorcheva ${ }^{1}$, Krasimir Rusanov ${ }^{1}$, Stanko Stanev $^{2}$, Ivan Atanassov ${ }^{1}$ \\ ${ }^{1}$ AgroBioInstitute, Agriculture Academy, Sofia 1164, Bulgaria \\ ${ }^{2}$ ZP Janeta Staneva, Kazanlak 6100, Bulgaria
}

\begin{abstract}
The efficient lavender (Lavandula angustifolia Mill.) breeding for essential oil production requires routine and accurate comparison the flower volatile composition of larger number individual plants from genetic resource pools and segregating populations. Here we describe the performance testing of a simple procedure for comparative GC-MS analysis of flower volatile composition of individual lavender plants. It involves collection of fixed number flowers at selected stage of development and direct solvent extraction and GC-MS analysis of the extracts. The summarized data on relative standard deviations for the analyzed compound abundancies determined from three replica analysis of individual plants from Bulgarian lavender varieties are presented. Further application of this comparative GC-MS analysis procedure demonstrates significant changes in the accumulation of certain volatiles during flower development. The comparative analysis also showed no significant daytime variation of the flower volatile composition and minor variations after testing the same plants within five consecutive days. The possibilities for routine applications of the tested procedure for comparative GC-MS analysis of flower volatiles in larger number of plants from lavender segregating populations or genetic resources collections are discussed.
\end{abstract}

Keywords: lavender, Lavandula angustifolia, flower volatiles, comparative GC-MS analysis, flower development

\section{Introduction}

Lavender (Lavandula angustifolia Mill.) is one of the few members of the genus Lavandula (Lamiaceae) which is cultivated worldwide for essential oil production [1]. The outspreading lavender cultivation beyond the traditional growth areas, elevated levels of harvest mechanization and essential oil market open for new lavender products resulted in increasing demands for further lavender improvement including targeted breeding and marker assisted selection [2,3]. The last is largely facilitated by the expanding lavender genomic resources [4, 5], set of characterized essential oil biosynthesis genes [6-10] and available molecular markers [2]. One drawback restraining larger scale lavender breeding programs and characterization of lavender genetic resources, as well as detailed assessment the impact of various environmental factors is the lack of efficient procedure for comparative analysis of lavender flower volatiles, which could be routinely applied for characterization of large sets of individual lavender plants. Due mainly to the direct practical usage of the generated data, so far the flower volatile studies on lavender and other Lavandula species employ the analysis of essential oils distilled from lavender inflorescence material [11,12]. This approach has been widely applied in studies of lavender varieties [13-17] and natural populations of Lavandula species [18-21], as well as for evaluation of the impact of environmental factors and processing practices [22-26]. However, the composition of the lavender oil is significantly influenced by the parameters of harvesting, inflorescence storage and essential oil distillation [11, 27-29]. Moreover, the changes of volatile abundancies during flower development combined with the unsynchronized lavender flower and inflorescence development add additional variations and further reduce the precision of the comparative analysis of individual plants. Our early attempt to develop routine procedure for lavender volatile analysis based on solvent extraction of milled frozen inflorescence material was not successful and showed rather high variations within replica analysis of inflorescence material collected from a single plant [30]. The secretion and accumulation of lavender essential oil compounds takes place mainly in peltate glandular trichomes located in high density on the adaxial calyx epidermis and to lesser extent in capitate trichomes on the epidermis of flower and leaf tissues [31]. To study the differential accumulation of volatile terpenes during lavender inflorescence and flower development, Guitton et al. [31] have successfully employed direct extraction of flower volatiles via dipping the flowers and inflorescence parts in solvent. However, the authors didn't evaluate the efficiency of the sample preparation procedure for routine comparative analysis of individual plants. Here we present results from application of a simple procedure for comparative analysis of lavender flower volatiles employing direct solvent extraction of a fixed number of 
flower buds and GC-MS analysis of the extracts. The opportunities for using the sample preparation procedure for characterization of larger sets of individual lavender plants are discussed.

\subsection{Plant material and flower collection}

\section{Material and methods}

Lavender flowers from seven Bulgarian lavender varieties and five breeding lines used in the study were collected during the period 21-25 June 2015, Figure 1a, from the lavender experimental field of the " $\mathrm{ZP}$ Janeta Staneva" nursery, nearby the village of Cherganovo, Municipality of Kazanlak, Bulgaria. A fixed number $(10,20,30$ and 40$)$ of flower buds at the analyzed developmental stages were collected with sharp tweezers without pressing the calyx. Flower buds were sampled from the apical zone of the inflorescence, zone 2 according to Guitton et al. [31], at three developmental stages: stage 1 - corolla pointing out of the calyx, stage 2 - corolla fully opened and stage 3 - corolla faded and brown. The pointed stages 1,2 and 3 correspond to stages 2, 3 and 5 described by Guitton et al. [31]. The collected flower buds were directly placed in $10 \mathrm{ml}$ screw cap glass tube, followed by addition of $3 \mathrm{ml} \mathrm{n}$-hexane (Sigma), containing $160 \mathrm{mg} / \mathrm{ml} 4$-methyl-2 pentanol (Sigma) as internal standard. The tightly closed tubes were stored at $4^{\circ} \mathrm{C}$ for 24 to 120 hours prior extraction. Each flower sample of the studied lavender varieties was analyzed in three replicas. All replica samples were collected from different plants of the same tested variety.

\subsection{GC-MS and data analysis}

Following storage at $4^{\circ} \mathrm{C}$, the extracts containing lavender flower volatiles were collected after vortexing the glass tubes for $15 \mathrm{~min}$ at $2000 \mathrm{rpm}$ (Vortex Genius 3, VWR). The extracts were dried through the addition of anhydrous sodium sulfate (Sigma), followed by centrifugation at $3000 \mathrm{~g}$ for $15 \mathrm{~min}$. The clear supernatant was transferred into $2 \mathrm{ml}$ vials, and stored at $-80^{\circ} \mathrm{C}$ until analysis. GC-MS analysis of the flower extracts was carried out on an Agilent 7890A gas chromatograph equipped with a 5975C mass spectrometer and an Agilent 7683B Series autosampler. All compounds were separated on a polar DB-WAXetr column (Agilent), $30 \mathrm{~m} \mathrm{x} 0.25 \mathrm{~mm}$, film thickness $0.25 \mu \mathrm{m}$, PEG as stationary phase. Carrier gas was helium at a flow rate of 3 $\mathrm{mL}$ min-1. Injector temperature was $250^{\circ} \mathrm{C}$, using splitless injection of $1 \mu \mathrm{L}$ per sample. Oven program was as follows: $65^{\circ} \mathrm{C}$ to $170^{\circ} \mathrm{C}$ at $1.5^{\circ} \mathrm{C}$ min-1. The mass selective detector was operated at a transfer line temperature of $250^{\circ} \mathrm{C}$ and electron impact ionization voltage of $70 \mathrm{eV}$. Individual compounds were detected and identified using AMDIS Ver. 2.71 software (National Institute of Standards and Technology (NIST), Gaithersburg, MD) and a custom-built MS library consisting of compounds identified previously in lavender oils, as well as by comparison with standard compounds purchased from Sigma-Aldrich. Retention index was calculated according to the retention times of standard n-alkane C10-C40 mixture (Sigma-Aldrich). All output AMDIS data files with identified compounds were imported in Mass Profiler Professional ver. 2.2 (Agilent), normalized against the internal standard (R)-(-)-4-Methyl-2-pentanol and used to perform ANOVA statistical analysis for significance and PCA analysis. Clustering analysis was performed using SPSS Statistics ver. 21 (IBM).

\subsection{Sample preparation and GC-MS analysis}

\section{Results}

The procedure of sample preparation for GC-MS analysis was set up following repeated sampling, processing and GC-MS analysis of samples consisting of 10,20,30 and 40 lavender flowers at developmental stages 1, 2 and 3, details in Materials and Methods. The obtained results showed that samples derived from extraction of 20, 30 and 40 flower buds with $3 \mathrm{ml}$ hexane resulted in reproducible detection of 24 compounds, including those pointed in the international standard for lavender oil ISO3515:2002. The sampling of only 10 flower buds resulted in reduced number of reproducibly detected compounds. Accordingly, samples derived from extraction of 30 flowers were further used in the study. The comparison of the relative standard deviation (RSD) values from the three replica analyses of all samples showed that the average RSD vary from $5.5 \%$ to $15.9 \%$ for the different compounds, TABLE 1 . Accordingly, the highest RSD values for compound abundancies calculated from the data of the three replicas excided $20 \%$ only for 3-octanol, beta-cis-ocimene and 1-octen-3ol, TABLE 1 . The comparison of the data from samples derived after different duration $(24 \mathrm{~h}-120 \mathrm{~h})$ of hexane dipped flowers storage at $4 \mathrm{oC}$ didn't show significant differences of their volatile composition. The described sample preparation procedure was further tested for comparative GC-MS analysis of the flower volatile composition at developmental stage 2 of three individual plants (replica samples) from seven Bulgarian lavender varieties and five breeding lines. The results demonstrated clear PCA (principal component analysis) clustering of the three replica plant samples of each variety and breeding line (data not shown). The obtained data were further used to build dendrogram resembling the clustering of the tested varieties and breeding lines according to their flower volatile composition at developmental stage 2, Fig. 1a. The comparison of the calculated relative total ion values of the identified compounds demonstrates very wide range of the levels of flower accumulation 
for a large part of them, TABLE 1. For example, the calculated relative total ion values for terpinen-4-ol ranged from $0.01 \%$ to $7.82 \%$ in the tested varieties.

Table 1. Summary of the data, identified peaks, relative total current (TIC) and relative standard deviation (RSD) values obtained after comparative GC-MS analysis of the flower volatiles composition of the tested Bulgarian lavender varieties and breeding lines.

\begin{tabular}{|c|c|c|c|c|c|c|c|c|}
\hline \multirow[t]{2}{*}{ Compound ${ }^{a, b}$} & \multicolumn{3}{|c|}{ RSD (\%) values ${ }^{1}$} & \multicolumn{2}{|c|}{ Range of TIC $(\%)^{2}$} & \multicolumn{3}{|c|}{$\begin{array}{c}\text { TIC (\%) at different stages of flower development } \\
\text { var. Sevtopolis }\end{array}$} \\
\hline & $\min$ & $\max$ & aver & $\min$ & $\max$ & st. 1 & st. 2 & st.3 \\
\hline Terpinen-4-ol ${ }^{\mathrm{a}}$ & 12.5 & 19.3 & 15.9 & $0.01 \pm 0$ & $7.82 \pm 0.07$ & $1.49 \pm 0.04$ & $2.02 \pm 0.1$ & $2.45 \pm 0.1$ \\
\hline Lavandulyl acetate ${ }^{\mathrm{a}}$ & 5.8 & 16.5 & 11.1 & $0.74 \pm 0.03$ & $6.48 \pm 0.17$ & $4.91 \pm 0.02$ & $5.03 \pm 0.16$ & $4.88 \pm 0.07$ \\
\hline b-Farnesene ${ }^{\mathrm{a}, \mathrm{b}}$ & 9 & 12.4 & 10.7 & $0.85 \pm 0.03$ & $9.94 \pm 0.13$ & $10.86 \pm 0.55$ & $9.73 \pm 0.13$ & $7.86 \pm 0.24$ \\
\hline 1-Octen-3-ol ${ }^{\mathrm{a}}$ & 10.8 & 20.0 & 15.4 & $0.03 \pm 0$ & $0.54 \pm 0.02$ & $0.21 \pm 0.03$ & $0.18 \pm 0.03$ & $0.14 \pm 0.02$ \\
\hline 3-Octanone ${ }^{\mathrm{a}}$ & 2.8 & 20.7 & 11.8 & $0.01 \pm 0$ & $0.24 \pm 0.02$ & $0.15 \pm 0.02$ & $0.21 \pm 0.02$ & $0.27 \pm 0.01$ \\
\hline a-Bergamotene ${ }^{\mathrm{a}}$ & 6.5 & 17.0 & 11.8 & $0 \pm 0$ & $0.32 \pm 0.02$ & $0.31 \pm 0.02$ & $0.25 \pm 0.01$ & $0.19 \pm 0$ \\
\hline a-Santalene ${ }^{\mathrm{a}}$ & 7.9 & 16.0 & 11.9 & $0 \pm 0$ & $1.18 \pm 0.04$ & $1.03 \pm 0.24$ & $0.96 \pm 0.07$ & $0.66 \pm 0.03$ \\
\hline a-Terpineol ${ }^{\mathrm{a}}$ & 10.1 & 15.7 & 12.9 & $0.01 \pm 0$ & $0.33 \pm 0.02$ & $0.29 \pm 0.02$ & $0.32 \pm 0.02$ & $0.28 \pm 0.01$ \\
\hline Benzaldehyde $^{\mathrm{a}}$ & 1.7 & 19.9 & 10.8 & $0.04 \pm 0.01$ & $0.24 \pm 0.01$ & $0.17 \pm 0.03$ & $0.17 \pm 0.02$ & $0.15 \pm 0.01$ \\
\hline b-cis-Ocimene $\mathrm{a}^{\mathrm{a}}$ & 10.7 & 20.3 & 15.5 & $1.92 \pm 0.08$ & $6.71 \pm 0.59$ & $4.99 \pm 0.11$ & $5.86 \pm 0.11$ & $6.09 \pm 0.15$ \\
\hline b-Linalool ${ }^{\mathrm{a}}$ & 4.5 & 17.1 & 10.8 & $12.16 \pm 0.22$ & $31.67 \pm 0.49$ & $20.09 \pm 1.56$ & $21.23 \pm 1.38$ & $25.33 \pm 1.46$ \\
\hline $\begin{array}{l}\text { b-Sesqui- } \\
\text { phellandrene }^{\text {a }}\end{array}$ & 2 & 11.2 & 6.6 & $0 \pm 0$ & $1.91 \pm 0.02$ & $0.04 \pm 0$ & $0.04 \pm 0.01$ & $0.03 \pm 0.01$ \\
\hline b-trans-Ocimene & 1.9 & 14.9 & 8.4 & $0.67 \pm 0.01$ & $3.15 \pm 0.06$ & $0.93 \pm 0.03$ & $0.93 \pm 0.04$ & $0.85 \pm 0.03$ \\
\hline Borneol $^{\mathrm{a}}$ & 3 & 14.8 & 8.9 & $0.14 \pm 0.02$ & $0.8 \pm 0.05$ & $0.53 \pm 0.02$ & $0.39 \pm 0.04$ & $0.35 \pm 0$ \\
\hline Borneol acetate $^{\mathrm{a}}$ & 4.5 & 13.3 & 8.9 & $0 \pm 0$ & $0.33 \pm 0.05$ & $0.04 \pm 0$ & $0.04 \pm 0$ & $0.03 \pm 0.01$ \\
\hline Camphor $^{\mathrm{a}}$ & 3.6 & 18.6 & 11.1 & $0.01 \pm 0$ & $0.21 \pm 0.02$ & $0.1 \pm 0$ & $0.13 \pm 0.01$ & $0.14 \pm 0$ \\
\hline Caryophyllene $^{\mathrm{a}}$ & 5 & 12.3 & 8.6 & $2.52 \pm 0.04$ & $6.76 \pm 0.19$ & $7.47 \pm 0.27$ & $6.5 \pm 0.19$ & $5.03 \pm 0.08$ \\
\hline $\begin{array}{l}\text { Caryophyllene } \\
\text { oxide }^{\mathrm{a}, \mathrm{b}}\end{array}$ & 4.2 & 13.2 & 8.7 & $0.18 \pm 0.02$ & $0.61 \pm 0.04$ & $0.27 \pm 0.03$ & $0.29 \pm 0.01$ & $0.2 \pm 0.01$ \\
\hline Geranyl acetate & 4.3 & 14.3 & 9.3 & $1.09 \pm 0.04$ & $2.06 \pm 0.06$ & $1.11 \pm 0.05$ & $1.13 \pm 0.04$ & $1.11 \pm 0.04$ \\
\hline Germacrene $\mathrm{D}^{\mathrm{a}}$ & 7.4 & 13.3 & 10.3 & $0.05 \pm 0.01$ & $1.09 \pm 0.04$ & $1.18 \pm 0.09$ & $1.05 \pm 0.04$ & $0.79 \pm 0.03$ \\
\hline Lavandulol $^{\mathrm{a}}$ & 9.6 & 15.2 & 13.2 & $0.05 \pm 0$ & $0.97 \pm 0.04$ & $0.99 \pm 0.05$ & $0.92 \pm 0.04$ & $1.06 \pm 0.11$ \\
\hline Limonene $^{\mathrm{a}}$ & 8.6 & 16 & 12.3 & $0.17 \pm 0.01$ & $0.35 \pm 0.03$ & $0.6 \pm 0.02$ & $0.32 \pm 0.02$ & $0.21 \pm 0.01$ \\
\hline Linalyl acetate ${ }^{\mathrm{a}, \mathrm{b}}$ & 1.6 & 9.3 & 5.5 & $27.25 \pm 0.67$ & $51.44 \pm 0.23$ & $26.21 \pm 0.54$ & $27.86 \pm 0.66$ & $27.99 \pm 1.17$ \\
\hline Nerol acetate & 0.9 & 12.4 & 6.7 & $0.71 \pm 0.01$ & $1.23 \pm 0.03$ & $0.76 \pm 0.03$ & $0.76 \pm 0.02$ & $0.73 \pm 0.03$ \\
\hline \multicolumn{9}{|c|}{$\begin{array}{l}\text { 1- summary of RSD values calculated for three replicas per sample; "min", "max" and "aver" - minimal, } \\
\text { maximal and average RSD values calculated for the respective compound in all analyzed samples. } \\
\text { 2- minimal and maximal TIC values (in percentage) of the volatiles after GC/MS analysis of flowers at } \\
\text { developmental stage } 2 \text { for seven lavender essential oil varieties currently cultivated in Bulgaria: Sevtopolis, } \\
\text { Hemus, Yubileina, Raya, Druzhba, Karlovo and Hebar } \\
\text { a - compounds with flower abundancies significantly different }(\mathrm{p}<0.05) \text { in samples at different stage of flower } \\
\text { development, data for all tested varieties } \\
\text { b - compounds with flower abundancies significantly different }(\mathrm{p}<0.01) \text { between the } 21-22 \text { May and 23-25 May } \\
\text { samples at stage } 2 \text { of flower development }\end{array}$} \\
\hline
\end{tabular}

\subsection{Volatile compositions at different stages of flower development}

The above flower sampling and processing procedure was further applied to assess the variations of flower volatile compositions between three distinct stages of flower development: st. 1 - corolla pointing out of calyx, st.2 - corolla fully opened and st.3 - corolla faded and brown. Flowers of three widely cultivated Bulgarian lavender varieties, var. Hemus, var. Yubileina and var. Sevtopolis, were sampled at the pointed stages of development and GC-MS analyzed. The performed PCA showed distinct clustering of the samples according to the tested varieties, as well as intra-variety clustering of the samples corresponding to the three analyzed stages of flower development, Fig. 1b. The data analysis demonstrated significant variation of the accumulation levels of a large part of the identified volatiles within the different stages of flower development, data for var. Sevtopolis are shown in TABLE 1. The closer data observation shows diverse trends of accumulation of the different compounds, similar to the reported by Guitton et al. [31] complex volatile accumulation patterns during lavender flower and inflorescence development. 
a.

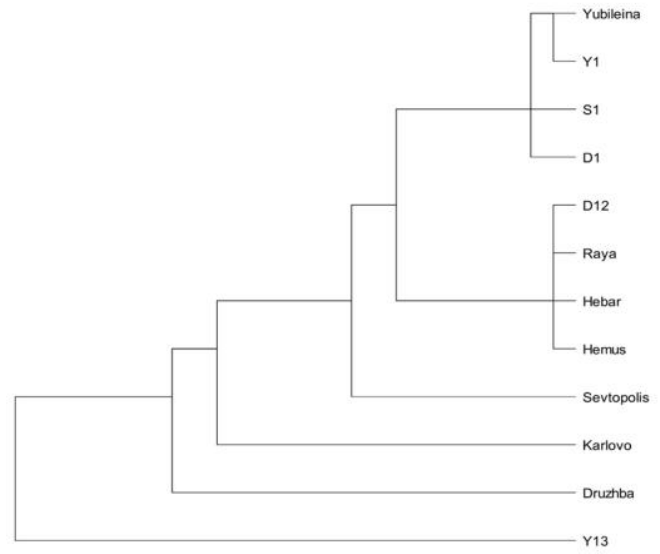

c.

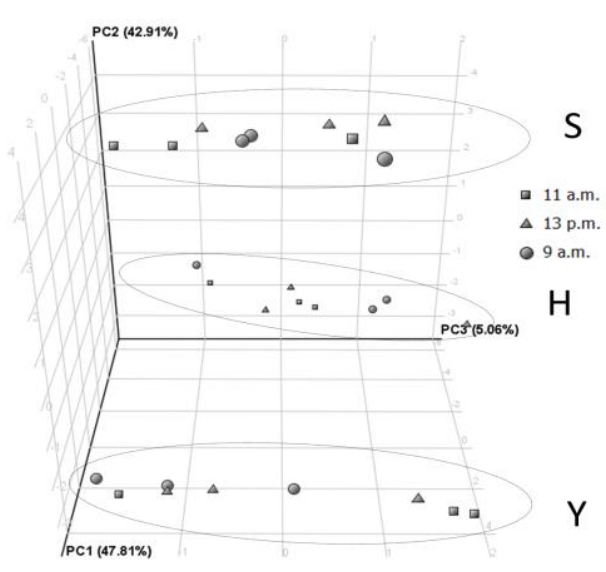

b.

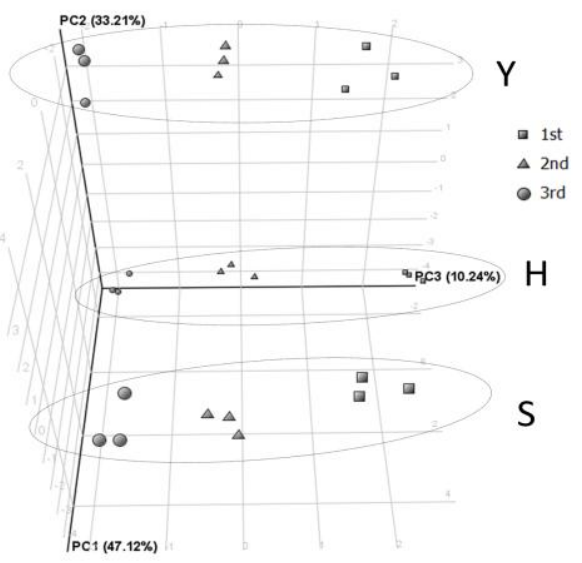

d.

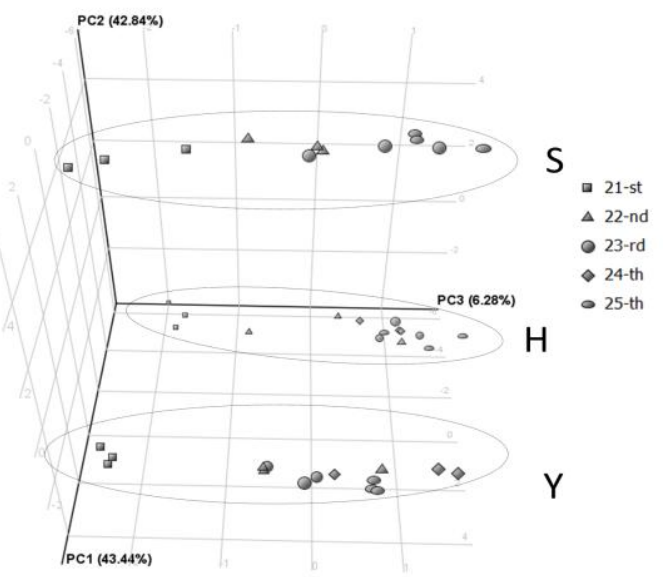

Figure 1. Comparative GC-MS analysis of flower volatiles composition of Bulgarian lavender varieties (Druzhba, Hebar, Hemus, Karlovo, Sevtopolis, Yubileina) and superior breeding lines (D1, D12, S1, Y1, Y13). (a) clustering of the tested varieties and breeding lines according to their flower stage 2 volatile compositions; (b-d) PCA analysis of the data from three replica GC-MS analysis of the volatile compositions of flowers from three lavender varieties Hemus /H/, Sevtopolis /S/ and Yubileina /Y/ samples of: (b) flowers at developmental stages 1, 2 and 3; (c) flower stage 2 samples collected at 9 a.m., 11 a.m. and 13 p.m.; and (d) flower stage 2 samples collected at 13:00 p.m. during five consecutive days 21-25/05/2015 with weather conditions and temperature at the time of sample collection: $21 / 05$ - buffering wind, $18^{\circ} \mathrm{C} ; 22 / 05$ - windy, $26^{\circ} \mathrm{C} ; 23 / 05$ - calm, $30^{\circ} \mathrm{C} ; 24 / 05$ - calm, $28^{\circ} \mathrm{C} ; 25 / 05-\mathrm{calm}, 28^{\circ} \mathrm{C}$. The clusters of samples belonging to the three varieties are designated with $\mathrm{H}, \mathrm{S}$ and $\mathrm{Y}$.

\subsection{Flower volatile composition at different daytime points and days of flower collection.}

Flowers from the three tested lavender varieties at developmental stage 2 were collected at 9.00, 11.00 and 13.00 o'clock and subjected to comparative GC-MS analysis of the volatiles composition. The PCA analysis of the obtained data showed distinct samples clustering only according to the sampled lavender varieties, but not in relation to the tested daytime points of collection, Fig. 1c. Accordingly, the data analysis showed no significant difference between the levels of accumulation of the identified compounds in the samples collected at the three daytime points. A similar comparative CG-MS analysis was carried out for stage 2 flower samples collected at 13:00 $\mathrm{h}$ in five consecutive days, 21-25 May. The PCA analysis of this data set showed that besides the variety related clustering, there is a distinct clustering of the samples collected on the 21-st of May and to some extent for those collected on the 22-nd of May, Fig. 2d. The samples of other three days of collection did not form distinct clusters. The review of the weather conditions for the pointed days of flower sampling suggests the main differences between 21-22 May and 23-25 May sampling days were the lower temperature $\left(18^{\circ} \mathrm{C}\right)$ on the 21-st of May in comparison to the rest of the days $\left(26-30^{\circ} \mathrm{C}\right)$ and the buffeting wind preceding the collection hours on the 21-st of May and still the strong wind on the 22-nd of May, Fig. 2d. This makes it possible to speculate that the observed differences for the 21-22 May flower volatile compositions could be a result of the lower temperature on the 21-st of May. Similarly, changes of the lavender oil composition related to changes of the climatic conditions during the flowering period were reported earlier by Hassiotis et al. [25]. The other factor which may influence the analyzed flower volatile composition is the mechanical breakages of part of the peltate glandular trichomes and subsequent changes of the composition of the released volatiles.

DOI: 10.9790/3008-1104030914 www.iosrjournals.org $\quad 12 \mid$ Page




\section{Discussion}

The employed simple lavender flower sampling and extraction procedure set up in the present study considers two critical issues: /a/ to avoid the impact of the inflorescence volatiles complexity caused by the developmental changes of flower volatiles biosynthesis and accumulation and /b/ to reduce the variations of the analyzed flower volatile compositions caused by sample processing, e.g. from essential oil distillation or the mechanical breakages of the glandular trichomes after pressing the flower tissues during multistep flower processing or milling of flower material. Accordingly, the sample preparation involves quick collection of a fixed number of flowers at selected stage of development and direct solvent extraction. The application of this procedure for analysis of a number of samples in triplicates consisting of flowers collected from three different plants of each of the tested variety showed lower RSD values of the scored volatile abundancies in comparison to the early tested procedure, employing extraction of equal portions of milled frozen inflorescences from individual lavender plants [30]. The earlier report by Guitton et al. [31] and the results from the present study point out that sampling of flowers at one and the same stage of development is essential for the precision of this comparative analysis procedure. The presented results also suggest that the sampling of the entire tested set of individual plants for a period of 2-4 hours within the same day is preferable and will not influence significantly the analyzed flower volatile composition. However, the higher day to day changes of climatic conditions or differences of climate parameters between the tested locations have to be taken into account when the study involves comparison of data from characterization of separate sets of plants. The obtained data could be readily used for cluster analysis and selection of groups of plants with similar volatile composition or identification of plants with deviation of the volatile composition or individual compound abundancies, example shown on Fig. 1a, as well as for QTL analysis of lavender segregating populations. The good performance of such sample preparation procedure suggests it could be easily applied, after simple optimization of the tissue to solvent ratio, for other plant species and sample types related to similar mode of trichome secretion and accumulation of the essential oil compounds.

\section{Conclusion}

In the present study we described successful testing of simple sample preparation procedure for comparative analysis of lavender flower volatiles, involving collection of a fixed number of lavender flowers at selected stage of development, followed by direct solvent extraction and GC-MS analysis of the volatiles. The procedure is well suited for flower sampling from larger number plants at field conditions including sampling of plants from remote plantations. The overall experience with the use of the described sample collection and preparation procedure as well as data analysis suggests they could be efficiently applied for comparative analysis of flower volatile composition of larger number of individual plants where essential oil analysis is not efficient or applicable, including characterization of segregating populations in lavender breeding programs and genetic resources pools in environmental studies.

\section{Acknowledgements}

This work was supported by the National Science Fund at the Ministry of Education and Science, Bulgaria, via project No DO02-105.

\section{References}

[1]. M. Lis-Balchin, Lavender: the genus Lavandula (London UK: Taylor and Francis, 2002)

[2]. A. Adal, Z. Demissie, and S. Mahmoud, Identification, validation and cross-species transferability of novel Lavandula EST-SSRs, Planta, 241(4), 2015, 987-1004.

[3]. S. Stanev, T. Zagorcheva, and I. Atanassov, Lavender cultivation in Bulgaria - 21st century developments, breeding challenges and opportunities, Bulgarian Journal of Agriculture Sciences, 22(4), 2016, (in press).

[4]. Y. Guitton, F. Nicolè, S. Moja, T. Benabdelkader, N. Valot, S. Legrand, F. Jullien, and L. Legendre, Lavender inflorescence: A model to study regulation of terpenes synthesis, Plant signaling \& behavior, 5(6), 2010, 749-751.

[5]. A. Lane, A. Boecklemann, G. Woronuk, L. Sarker, and S. Mahmoud, A genomics resource for investigating regulation of essential oil production in Lavandula angustifolia, Planta, 231(4), 2010, 835-845.

[6]. Z. Demissie, M. Cella, L. Sarker, T. Thompson, M. Rheault, and S. Mahmoud, Cloning, functional characterization and genomic organization of 1, 8-cineole synthases from Lavandula, Plant Molecular Biology 79(4-5), 2012, 393-411.

[7]. Z. Demissie, L. Sarker, and S. Mahmoud, Cloning and functional characterization of $\beta$-phellandrene synthase from Lavandula angustifolia. Planta, 233(4), 2011, 685-696.

[8]. F. Jullien, S. Moja, A. Bony, S. Legrand, C. Petit, T. Benabdelkader, K. Poirot, S. Fiorucci, Y. Guitton, and F. Nicolè, Isolation and functional characterization of a $\tau$-cadinol synthase, a new sesquiterpene synthase from Lavandula angustifolia, Plant Molecular Biology 84(1-2), 2014, 227-241.

[9]. C. Landmann, B. Fink, M. Festner, M. Dregus, K. Engel, and W. Schwab, Cloning and functional characterization of three terpene synthases from lavender (Lavandula angustifolia), Archives of Biochemistry and Biophysics 465(2), 2007, 417-429.

[10]. L. Sarker, Z. Demissie, and S. Mahmoud, Cloning of a sesquiterpene synthase from Lavandula x intermedia glandular trichomes, Planta, 238(5), 2013, 983-989.

[11]. E. Denny, Distillation of the lavender type oils: theory and practice. in M. Lis-Balchin (Ed.) Lavender: the genus Lavandula, (London: Taylor \& Francis, 2002) 101-116. 
[12]. R. Shellie, L. Mondello, P. Marriott, and G. Dugo, Characterisation of lavender essential oils by using gas chromatography-mass spectrometry with correlation of linear retention indices and comparison with comprehensive two-dimensional gas chromatography, Journal of Chromatography A, 970(1-2), 2002, 225-234.

[13]. M. Adaszyńska, M. Swarcewicz, M. Dzięcioł, and A. Dobrowolska "Comparison of chemical composition and antibacterial activity of lavender varieties from Poland, Natural Product Research, 27(16), 2013, 1497-1501.

[14]. D. Charles, E. Renaud, and J.E. Simon, Comparative study of essential oil quantity and composition from ten cultivars of organically grown lavender and lavandin, in M. Lis-Balchin (Ed.) Lavender: the genus Lavandula, (London: Taylor \& Francis, 2002) 232-243

[15]. P. Chatzopoulou, A. Goliaris, and S. Katsiotis, Contribution to the analysis of the volatile constituents from some lavender and lavandin cultivars grown in Greece, Scientia Pharmaceutica, 71(3), 2003, 229-234.

[16]. N. Kara, and H. Baydar, Determination of lavender and lavandin cultivars (Lavandula sp.) containing high quality essential oil in Isparta, Turkey, Turk J Field Crops, 18, 2013, 58-65.

[17]. P. Venskutonis, A. Dapkevicius, and M. Baranauskiene, Composition of the essential oil of Lavender (Lavandula angustifolia Mill.) from Lithuania, Journal of Essential Oil Research, 9(1), 1997, 107-110.

[18]. I. Bajalan, and A. Pirbalouti, Variation in chemical composition of essential oil of populations of Lavandulax intermedia collected from Western Iran, Industrial Crops and Products, 69, 2015, 344-347.

[19]. J. Muñoz-Bertomeu, I. Arrillaga, and J. Segura, Essential oil variation within and among natural populations of Lavandula latifolia and its relation to their ecological areas, Biochemical Systematics and Ecology, 35(8), 2007, 479-488.

[20]. S. Salido, J. Altarejos, M. Nogueras, A. Sánchez, and P. Luque, Chemical composition and seasonal variations of spike lavender oil from Southern Spain, Journal of Essential Oil Research 16(3), 2004, 206-210.

[21]. R. Verma, L. Rahman, C. Chanotiya, R. Verma, A. Chauhan, A. Yadav, A. Singh, and A. Yadav, Essential oil composition of Lavandula angustifolia Mill. cultivated in the mid hills of Uttarakhand, India, Journal of the Serbian Chemical Society 75(3), 2010, 343-348.

[22]. A. Angioni, A. Barra, V. Coroneo, S. Dessi, and P. Cabras, Chemical composition, seasonal variability, and antifungal activity of Lavandula stoechas L. ssp. stoechas essential oils from stem/leaves and flowers, Journal of Agricultural and Food Chemistry, 54(12), 2006, 4364-4370.

[23]. I. Bombarda, N. Dupuy, J. Da, and E. Gaydou, Comparative chemometric analyses of geographic origins and compositions of lavandin var. Grosso essential oils by mid infrared spectroscopy and gas chromatography, Analytica Chimica Acta 613(1), 2008, 3139.

[24]. E. Dušková, K. Dušek, P. Indrák, and K. Smékalová, Postharvest changes in essential oil content and quality of lavender flowers, Industrial Crops and Products, 79(2), 2016, 225-231.

[25]. C. Hassiotis, F. Ntana, D. Lazari, S. Poulios, and K. Vlachonasios, Environmental and developmental factors affect essential oil production and quality of Lavandula angustifolia during flowering period, Industrial Crops and Products, 62, 2014, $359-366$.

[26]. V. Zheljazkov, T. Astatkie, and A. Hristov, Lavender and hyssop productivity, oil content, and bioactivity as a function of harvest time and drying, Industrial Crops and Products, 36(1), 2012, 222-228.

[27]. E. Cassel, R. Vargas, N. Martinez, D. Lorenzo, and E. Dellacassa, Steam distillation modeling for essential oil extraction process, Industrial crops and products, 29(1), 2009, 171-176.

[28]. A. Wesolowska, D. Jadczak, and M. Grzeszczuk, Influence of distillation time on the content and composition of essential oil isolated from lavender (Lavandula angustifolia Mill.), Herba Polonica, 56(3), 2010, 56-66.

[29]. V. Zheljazkov, C. Cantrell, T. Astatkie, and E. Jeliazkova, Distillation time effect on lavender essential oil yield and composition, Journal of Oleo Science, 62(4), 2013, 195-199.

[30]. T. Zagorcheva, S. Stanev, K. Rusanov, and I. Atanassov, Comparative GC/MS analysis of lavender (Lavandula angustifolia Mill.) inflorescence and essential oil volatiles, Agricultural Science and Technology, 5(4), 2013, 459-462.

[31]. Y. Guitton, F. Nicolè, S. Moja, N. Valot, S. Legrand, F. Jullien, and L. Legendre, Differential accumulation of volatile terpene and terpene synthase mRNAs during lavender (Lavandula angustifolia and L. x intermedia) inflorescence development, Physiologia Plantarum, 138(2), 2010, 150-163. 